ISSN 2693-2326

\title{
An Unusual Cause of Facial swelling - Bot Fly Larva in an Infant - A Case Report
}

\author{
International Journal of Infectious Diseases and Research
}

Case Report

\begin{abstract}
Sanaa AIRaisi ${ }^{*}$, Ishita Basu², Matula Taloumtzi ${ }^{3}$ and John Blythe ${ }^{4}$
${ }^{1,4}$ The Royal London Hospital, Barts Health NHS Trust, London E1 $1 F R$

*Correspondence author

Sanaa AlRaisi

${ }^{2}$ University College London, London WC1E 6BT

The Royal London Hospital

Barts Health NHS Trust

${ }^{3}$ Eastman dental hospital, London WC1E $6 D G$

London E1 1FR

Submitted : 13 Jan 2021 ; Published : 10 Mar 2021

Abstract and Introduction

'Myiasis' is a term used to describe an infestation of humans or animals with dipterous larvae [1]. Due to increased international travel in recent times, health professionals in the UK may encounter these infections more commonly than before. We present a case of a 6 month infant who had been bitten by Dermatobia hominis Bot fly in Brazil and travelled back to the UK. The original diagnosis was of an infected insect bite, which ultimately delayed appropriate management. A detailed travel history is therefore paramount and these types of infections should be considered in differential diagnoses. Management should also involve the infectious diseases team.
\end{abstract}

\section{Case Report}

A 6 month-old infant was brought into the Emergency Dependent at the Royal London Hospital by her mother with regard to a right preauricular swelling that had been present for three weeks (Figure.1) The mother reported being in Brazil, Minas Gerais, on her mother's farm where the child had been bitten by an insect.

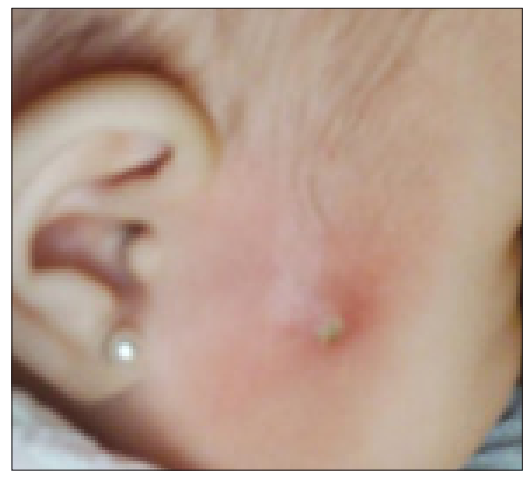

Figure 1

The bite had become erythematous and swollen on return to the UK and thought to be infected. The infant was taken to her General Medical Practitioner and a course of antibiotics were prescribed. The swelling and erythema persisted for another week and a central 'punctum' was evident. The infant was taken to another hospital originally from where another course of antibiotics was prescribed, before attending the Royal London three weeks after the original bite.

On examination was the infant was afebrile. There was a $2 \mathrm{~cm}$ fluctuant erythematous swelling present on the right pre-auricular area with a central $1 \mathrm{~mm}$ punctum. On closer examination there was fluid bobbing up and down rhythmically with occasional yellow/pink fluid discharge through the punctum (Fig.2) there were no signs of sepsis.

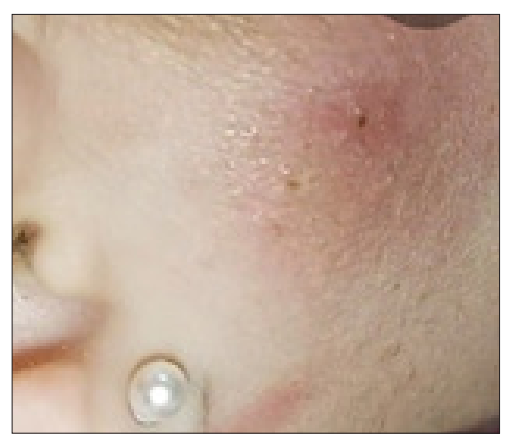

Figure 2

She was reviewed by the infectious diseases team who diagnosed 'South American Furuncular Myasis' due to Dermatobia Homininis or Bot Fly (Fig 3)

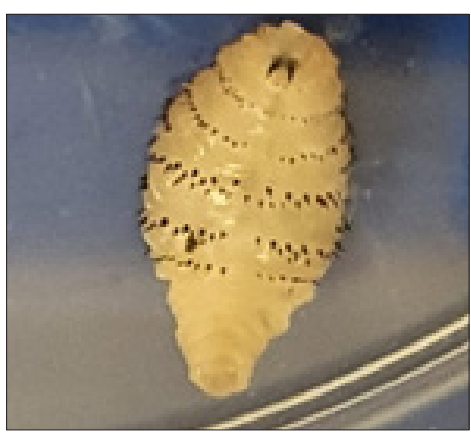

Figure 3

I J Infectious Disea; $2021 \quad$ www.unisciencepub.com 
The patient was taken for a general anaesthetic for removal of this larva. Intravenous antibiotics were administered on induction and a cruciate incision was used (Fig.4) for greater access as the punctum or 'airhole' was only $1 \mathrm{~mm}$ and the body of the Bot Fly larva is known to be large and spiky.

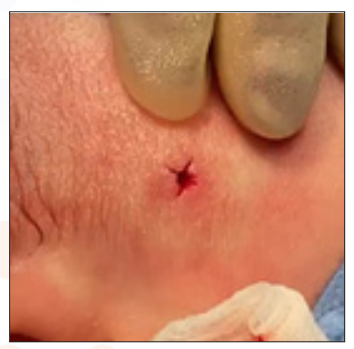

Figure 4

The larva was gently encouraged out of the cavity with warm saline and digital pressure [5] so as to remove it in it's entirely and not damage its body. As discussed with the Infectious Diseases team, there are no guidelines with regard to management of the cavity or wound. The cavity was irrigated with copious amounts of saline and the wound was sutured closed. Post-operative antibiotics were not advised. The larva was approximately $20 \mathrm{~mm}$ in length (Fig. 6). The larva was stored in formalin and given to the infectious diseases team for safe disposal.

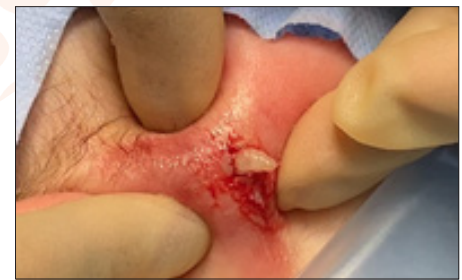

Figure 5

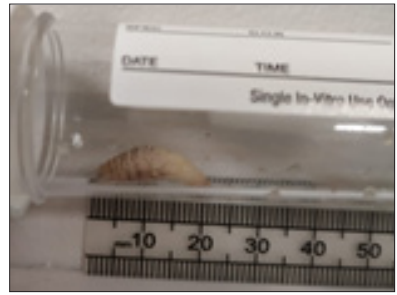

Figure 6

\section{Discussion}

'Myiasis' is used to describe an infestation of humans and animals with dipterous larvae. These larvae feed on host tissue, body fluids and ingested food. The infestation can result in painful and swollen cutaneous lesions. The main organisms implicated are Dermatobia hominis or Cordylobia anthropophaga [2]. The fly lay their eggs either directly to the skin or can use other insects as a vector, such as mosquitos. The larvae remain in the host for 2 weeks to 3 months after which they leave to continue their life cycle [3]. These types of fly are most commonly found in tropical climates, such as South America [4], and have been used to removed necrotic tissue. The extremities, back and scalp are the most common sites of infection. In the initial 24 hours after an infestation there will be a swelling, followed by the formation of an 'airhole'. Most people will experience pain and often movement of the larvae can be detected, especially in the Dermatobia hominis as it often has spikes on its body [5].

Symptoms in the paediatric population can include itching, distress and sleep disturbance. Secondary infections have also been documented, most commonly S. aureus and group B streptococcus [5].

There are three main techniques commonly used to remove larva such as those are (2):

1. $1 \%$ lidocaine to paralyze the larva prior to extraction

2. Petroleum jelly or adhesive to occlude the airhole forcing the larva to exit the cavity

3. Surgical removal with a cruciate incision as in this case

\section{Acknowledgement}

We are very thankful to Chris Chang and the Infection Disease Department in the Royal London Hospital

\section{Conclusion}

This case demonstrates the importance of a detailed travel history and that infectious diseases should be considered in any differential diagnoses.

A delay in the correct diagnosis in this case prolonged the child's distress and increased the chances of a secondary infection, and ultimately delayed correct treatment. A multidisplinary approach is recommended with discussion with infectious diseases and microbiology.

\section{References}

1. Carlos Nicolas Prieto-Granada, Martin C. Mihm Jr (2010). In Diagnostic Pathology of Infectious Disease.

2. Fabio Francesconia, Omar Lupi (2012). Myiasis, Clin Microbiol Rev, 25(1):79-105.

3. Amendt J, Goff M L, Compobasso C P, Gherardi M (2010). Forensic Implications of Myiasis, Current Concepts of Forensic Entomology, Springer, Chapter 14.

4. Sutherst R W, Spradbery J P, Maywald G F (1989). The potential geographical distribution of the old world screwworm fly, chrysomya bezziana. Med Vet Entomol, 3(3):273280 .

5. Basil Sunny, Lubna Sulthana, Apollo James, T. Sivakumar (2016). Maggot Infestation: Various Treatment Modalities. $J$ Am Coll Clin Wound Spec, 8(1-3):51-53.

Copyright: (C2021 Sanaa AlRaisi. This is an open-access article distributed under the terms of the Creative Commons Attribution License, which permits unrestricted use, distribution, and reproduction in anymedium, provided the original author and source are credited. 